\title{
Análise de pólen em pelagem de morcegos Phyllostomidae (Chiroptera) no Parque Estadual Fontes do Ipiranga, São Paulo, SP, Brasil ${ }^{1}$
}

- Helen Regina da Silva Rossi ${ }^{2,6}$, Angela Maria da Silva Corrêa ${ }^{3}$, Cauê Monticelli Luan Henrique Morais ${ }^{4}$ e Vlamir José Rocha ${ }^{5}$

Recebido: 20 junho 2019; aceito: 16 dezembro 2019

Como citar: Rossi, H.R.S., Corrêa, A.M.S., Monticelli, C., Morais, L.H. \& Rocha, V.J.2020. Análise de pólen em pelagem de morcegos Phyllostomidae (Chiroptera) no Parque Estadual Fontes do Ipiranga, São Paulo, SP, Brasil. Hoehnea 47: e702019. http://dx.doi.org/10.1590/2236-8906-70/2019.

ABSTRACT - (Analysis of pollen on the fur of Phyllostomidae bats (Chiroptera) at the Parque Estadual das Fontes do Ipiranga, São Paulo State, Brazil). Pollination is a well successful mutualistic relationship between bats and angiosperms but little is known about pollen diversity on the fur of the phytophagous species of bats. This study aimed to record the pollen types found on the fur of Phyllostomidae bats in order to identify possible interactions between these animals and plants. Mist nets were used to capture bats at the Parque Estadual das Fontes do Ipiranga, municipality of São Paulo, between October 2015 and September 2016. Pollen grains were collected with a brush and distilled water and subjected to laboratory analysis. Seventy-two pollen types were recorded, of which the most frequent were Alchornea $(9.3 \%, \mathrm{n}=20)$, Eucalyptus $(5.6 \%, \mathrm{n}=12)$, and Euterpe $(4.6 \%, \mathrm{n}=10)$. As a total, 267 bats belonging to five species were sampled, with Artibeus lituratus, Stunira lilium, and Artibeus fimbriatus presenting the highest diversity of pollen types on their bodies. In this study, unpublished interactions between bats and plants were identified.

Keywords: Atlantic forest, bat-plant interaction, PEFI, phytophagous bats, pollen diversity

RESUMO - (Análise de pólen em pelagem de morcegos Phyllostomidae (Chiroptera) no Parque Estadual Fontes do Ipiranga, São Paulo, SP, Brasil) A polinização é uma relação mutualística bem-sucedida entre morcegos e angiospermas. Apesar disso, pouco se conhece sobre a diversidade polínica presente na pelagem de espécies de morcegos fitófagos. O objetivo deste estudo foi registrar os tipos polínicos encontrados na pelagem de morcegos Phyllostomidae, a fim de identificar possíveis interações entre esses animais e as plantas. Para a captura dos quirópteros no Parque Estadual Fontes do Ipiranga, localizado na cidade de São Paulo, foram utilizadas redes de neblina entre outubro de 2015 e setembro de 2016. Os grãos de pólen foram coletados com pincel e água destilada e submetidos à análise em laboratório. Setenta e dois tipos polínicos foram registrados, sendo que os mais frequentes foram Alchornea $(9,3 \%, \mathrm{n}=20)$, Eucalyptus $(5,6 \%, \mathrm{n}=12)$ e Euterpe $(4,6 \%$, $\mathrm{n}=10$ ). Foram amostrados 267 morcegos pertencentes a cinco espécies, sendo que Artibeus lituratus, Stunira lilium e Artibeus fimbriatus apresentaram as maiores diversidades polínicas em seus corpos. Neste trabalho, foram identificadas interações inéditas entre morcegos e plantas.

Palasvras-chave: diversidade polínica, interação morcego-planta, Mata Atlântica, morcegos fitófagos, PEFI

\section{Introdução}

Apesar da interação entre morcegos e flores já ser bem documentada (Heithaus et al. 1975, Pedro \&
Taddei 1997, Sazima et al. 1999, Bredt et al. 2012), pouco se conhece sobre a diversidade polínica que esses animais carregam em seus corpos, visto que a maioria dos estudos realizados focam na observação,

1. Parte da Dissertação do primeiro Autor

2. Universidade Federal de São Carlos, Centro de Ciências Agrárias, Laboratório de Fauna, Rod. Anhanguera, km 174, $13600-970$ Araras, SP, Brasil

3. Instituto de Botânica, Núcleo de Pesquisa em Palinologia, Avenida Miguel Estéfano, 3687, 04301-902 São Paulo, SP, Brasil

4. Fundação Parque Zoológico de São Paulo, Av. Miguel Estéfano, 4241, 04301-905 São Paulo, SP, Brasil

5. Universidade Federal de São Carlos, Centro de Ciências Agrárias, Departamento de Ciências da Natureza, Matemática e Educação, Laboratório de Fauna, Rod. Anhanguera, km 174, 13600-970 Araras, SP, Brasil

6. Autor para correspondência: helen_regina@hotmail.com 
pré-selecionada, de uma única espécie vegetal quiropterofílica (Sazima \& Sazima 1978, Buzato \& Franco 1992, Silva et al. 1997, Sazima et al. 1999, Sanmartin-gajardo \& Sazima 2005).

A amostragem de grãos de pólen presentes na pelagem dos morcegos ainda é pouco usual (Pinto 2010) e tem sido pouco explorada no Brasil (Coelho \& Marinho-Filho 2002). Entretanto, apresenta vantagens práticas, pois em um mesmo estudo sobre levantamento da comunidade de quirópteros é possível obter informações sobre as várias espécies vegetais que, possivelmente, foram visitadas por aqueles indivíduos (Pinto 2010). Dessa forma, podendo ser relevante ferramenta de estudo sobre hábitos alimentares (Pinto 2010).

A maior parte dos estudos sobre polinização realizada por morcegos é focada em espécies nectarívoras (Sazima \& Sazima 1977, Silva et al. 1997, Estêvão 2009, Pinto 2010). Portanto, estudos que visem compreender melhor a relação entre morcegos não-glossofagíneos e as espécies de pólen que carregam possuem grande relevância para preencher lacunas de informação e ampliar panoramas de pesquisa nessa área. Além de subsidiar propostas significativas para ações conservacionistas que beneficiem tanto a quiropterofauna como a flora relacionada com as suas interações.

Considerando que a sazonalidade é um dos fatores que influenciam nas taxas de capturas desses mamíferos (Pedro 1998, Mello et al. 2008, Carvalho et al. 2011, Novaes et al. 2016, Rossi 2017), investigar se a mesma também influencia nas interações entre morcegos e plantas propicia a geração de informações sobre como os morcegos interagem com o ambiente ao longo das estações do ano. Além disso, a maior compreensão dessas interações pode ser utilizada como indicativo para auxiliar na tomada de decisão de ações que necessitem de maiores informações em menor tempo, como, por exemplo, em trabalhos que requeiram o rápido levantamento da fauna de determinado local, uma vez que podem indicar os melhores meses do ano para captura de morcegos e a obtenção de informações ecológicas como "morcegoplanta".

Embora estudos utilizem diferentes técnicas para a coleta de material polínico, todas são aplicados sobre a pelagem dos morcegos. Na literatura, até o momento, foram utilizados: pequenos cubos gelatinosos, montando lâminas imediatamente após a coleta do pólen (Heithaus et al. 1975, Muchhala \& Jarrín-V 2002), fitas dupla-face (Pinto 2010) e pincel e água destilada (MacSwiney et al 2017).
O objetivo desse estudo foi registrar os tipos polínicos encontrados na pelagem de morcegos Phyllostomidae, a fim de identificar possíveis interações entre esses animais e as plantas. Além disso, buscou-se verificar se há diferença na riqueza de tipos polínicos encontrados durante as estações seca e chuvosa, e testar a eficiência do método de coleta de material polínico, o qual é pouco utilizado e ainda sem registro de uso no Brasil.

\section{Material e métodos}

Área de estudo - O presente trabalho foi realizado no Parque Estadual Fontes do Ipiranga - PEFI, localizado


$23^{\circ} 40^{\prime} 18^{\prime \prime S}$ e $\left.46^{\circ} 36^{\prime} 48^{\prime \prime} \mathrm{W}-46^{\circ} 38^{\prime} 00^{\prime \prime} \mathrm{W}\right)$. O PEFI representa uma ilha florestal em meio a uma matriz densamente urbanizada, possui 526,4 hectares com vegetação característica de Floresta Ombrófila Densa de Encosta Atlântica (SMA 2008). De acordo com a classificação de Köppen o clima da região é Cwa (subtropical úmido) caracterizado por invernos secos (abril a setembro) e verões chuvosos (outubro a março), com temperatura média anual de $19,5^{\circ} \mathrm{C}$ e pluviosidade anual média 1540,5 mm (IAG/USP 2016).

Amostragem dos morcegos - As campanhas em campo foram realizadas no período de outubro de 2015 a setembro de 2016, durante quatro noites consecutivas por mês, sendo duas noites na área da Fundação Parque Zoológico de São Paulo e outras duas noites na área do Instituto de Botânica de São Paulo, totalizando 48 noites de amostragem. Para a captura dos morcegos foram utilizadas seis redes de neblinas de $12 \times 2,5 \mathrm{~m}$, armadas a $0,5 \mathrm{~m}$ de altura do solo e abertas durante quatro horas após o pôr do sol em estradas/trilhas préexistentes, totalizando um esforço de $34.560 \mathrm{~m}^{2} / \mathrm{h}$, de acordo com cálculos de Straube \& Bianconi (2002). Os grãos de pólen presentes na pelagem dos morcegos foram coletados utilizando pincel e água destilada, suas cerdas foram umedecidas em água destilada e em seguida passadas por todo o corpo do animal a fim de obter maior número de tipos polínicos, e posteriormente lavadas em $5 \mathrm{ml}$ de água destilada dentro de um tubo de ensaio de polipropileno de $15 \mathrm{ml}$ com tampa de rosca para acondicionar os grãos de pólen obtidos. Esse procedimento foi realizado mesmo quando os grãos de pólen não estavam visíveis a olho nu.

As amostras de grãos de pólen foram coletadas de um ou vários indivíduos da mesma espécie 
utilizando-se um tubo de ensaio por espécie de morcego em cada noite de amostragem. Logo, as amostras se referem a espécie do morcego e não a um indivíduo. As análises dos resultados foram agrupadas e expressadas mensalmente.

Preparação das lâminas para análise do espectro polínico - O material polínico foi submetido ao método de acetólise de Erdtman (1960), a seguir para cada amostra foram montadas três lâminas com gelatina glicerinada. As lâminas encontram-se depositadas na Palinoteca do Núcleo de Pesquisas em Palinologia do Instituto de Botânica em São Paulo. As fotomicrografias digitais em microscopia óptica foram realizadas utilizando-se um microscópio óptico (Olympus BX50, com câmera de vídeo Olympus SC30, Japão) acoplada a um microcomputador, utilizando-se o software CellSens Standard 1.5 de análise de imagens.

Contagem e identificação dos tipos polínicos - A identificação e contagem dos tipos polínicos foram realizadas no laboratório do Núcleo de Pesquisa em Palinologia do Instituto de Botânica de São Paulo, utilizando-se um microscópio óptico Olympus BX 50. Foram contados sempre que possível até 300 grãos de pólen por amostra e na maioria das vezes em que possuíam menos que 300 contou-se todos os grãos contidos nas lâminas. Em muitos casos os grãos de pólen não são distinguíveis por sua morfologia polínica (Pinto et al. 2010), tornando-se difícil determinar a espécie a qual pertence, portanto, a identificação limitou-se ao "tipo polínico". O "tipo polínico" refere-se mais comumente a várias espécies de um mesmo gênero ou até mesmo de outros gêneros e em raros casos à exata espécie vegetal (Barth 1989, Joosten \& De Klerk 2002, De Klerk \& Joosten 2007). Os tipos polínicos foram identificados por comparação, utilizando-se principalmente trabalhos publicados na Revista Hoehnea da série "Flora Polínica da Reserva do Parque Estadual das Fontes do Ipiranga, São Paulo, Brasil" (Melhem et al. 1984), além da coleção de lâminas de referência da Palinoteca do Núcleo de Pesquisa em Palinologia e outros catálogos polínicos pertinentes (Roubik \& Moreno 1991, Melhem et al. 2003). Procurou-se estabelecer os táxons botânicos ocorrentes no PEFI agrupando-os por família, gênero e mais raramente por espécie e para tanto utilizou-se o inventário florístico "Flora Fanerogâmica da Reserva do Parque Estadual das Fontes do Ipiranga, São Paulo, Brasil" (Melhem et al. 1981, Nakagima et al. 2001).
Influência da sazonalidade sobre a diversidade polínica nos morcegos - Para verificar se a sazonalidade influenciou as interações entre esses morcegos e as plantas e, assim, testar se houve diferença significativa entre os resultados obtidos durante as duas estações, utilizou-se Log na base 10 para normalizar os dados e aplicou-se o teste F para amostras pareadas.

\section{Resultados e Discussão}

Foram analisados 267 morcegos fitófagos ${ }^{7}$, de cinco espécies pertencentes à família Phyllostomidae, sendo contabilizados 1.692 grãos de pólen referentes a 72 tipos polínicos, distribuídos em 37 famílias vegetais. Resultado expressivo, visto que trabalhos similares encontraram menor riqueza polínica (Heithaus et al. 1975, Muchhala \& Jarrín-V 2002, Pinto et al. 2010), o que indica que a metodologia utilizada para a coleta do material polínico foi eficiente, podendo ser uma alternativa aos métodos já usados.

As maiores ocorrências foram em Artibeus lituratus (Olfers, 1818) com 133 indivíduos amostrados registrou-se 827 grãos de pólen e 52 tipos polínicos (72\%), seguido por Stunira lilium (É. Geoffroy, 1810) com 81 indivíduos amostrados, 122 grãos de pólen e 39 tipos polínicos (54\%) e Artibeus fimbriatus Gray, 1838 com 43 indivíduos amostrados, 380 grãos de pólen e 33 tipos polínicos (46\%). A visitação às flores por morcegos considerados não nectarívoros já foi documentada (Heithaus et al. 1975, Pedro \& Taddei 1997, Sazima et al. 1999, Bredt et al. 2012) e diversos trabalhos relataram essas três espécies utilizando recursos florais para complementarem a dieta (Heithaus et al. 1975, Vieira \& CarvalhoOkano 1996, Pedro \& Taddei 1997, Gonçalvez 2009). Além destes, também foram registrados nos quatro indivíduos de Plathhrinus lineatus (É. Geoffroy, 1810) amostrados três tipos polínicos (4\%) em 17 grãos de pólen. Para os seis indivíduos amostrados de Glossophaga soricina (Pallas, 1766), uma espécie pertencente a guilda dos nectarívoros, foram registrados apenas dez tipos polínicos (14\%) em 346 grãos de pólen. Provavelmente isso está relacionado à baixa quantidade de amostras obtidas ou com a maior

7. Fitófagos são animais que possuem a dieta caracterizada pelo uso exclusivo ou predominante de material vegetal como fonte de alimento, sendo essa a segunda estratégia trófica com maior representatividade dentre os quirópteros (Nogueira; Peracchi, 2008). 
especificidade desta espécie em relação às espécies florais que visitam (tabela 1).

Os tipos polínicos deste estudo pertenceram a 37 famílias vegetais, segundo Fleming et al. (2009) 44 famílias de angiospermas contêm flores visitadas por morcegos filostomídeos. As famílias vegetais que apresentaram maior frequência foram Fabaceae $(15,3 \%, \mathrm{n}=33)$, Asteraceae $(11,2 \%, \mathrm{n}=24)$, Euphorbiaceae $(10,2 \%, \mathrm{n}=22)$ e Myrtaceae $(10,2 \%$, $\mathrm{n}=22 \%$ ). A grande interação entre morcegos e espécies

Tabela 1. Tipos polínicos encontrados na pelagem de morcegos filostomídeos no Parque Estadual Fontes do Ipiranga, São Paulo, SP, Brasil, entre outubro de 2015 e setembro de 2016, com suas respectivas frequências de ocorrências (Freq) e quantidade de grãos de pólen de cada tipo polínico (GP). Artibeus lituratus (A.lit), Artibeus fimbriatus (A.fim), Glossophaga soricina (G.sor), Sturnira lilium (S.lil), Platyrrhinus lineatus (P.lin) e Indeterminado (Indet).

Table 1. Pollen types found on the fur of Phyllostomidae bats at theParque Estadual Fontes do Ipiranga, São Paulo, São Paulo State, Brazil, São Paulo State, between October 2015 and September 2016, with the respective frequency of occurrence (Freq) and the amount of pollen grain of each pollen type (GP). Artibeus lituratus (A.lit), Artibeus fimbriatus (A.fim), Glossophaga soricina (G.sor), Sturnira lilium (S.lil), Platyrrhinus lineatus (P.lin), and Undetermined (Indet).

\begin{tabular}{|c|c|c|c|c|c|c|c|c|c|c|c|c|c|c|}
\hline \multirow{2}{*}{$\frac{\overline{\text { Espécies }}}{\text { Tipos polínicos }}$} & \multicolumn{2}{|c|}{ A. lit } & \multicolumn{2}{|c|}{ S. lil } & \multicolumn{2}{|c|}{ A. fim } & \multicolumn{2}{|c|}{ G. sor } & \multicolumn{2}{|c|}{ P. lin } & \multirow{2}{*}{$\begin{array}{l}\text { Total } \\
\text { Freq }\end{array}$} & \multirow{2}{*}{$\begin{array}{c}\text { Total } \\
\text { GP }\end{array}$} & \multirow{2}{*}{$\frac{\%}{\text { Freq }}$} & \multirow{2}{*}{$\begin{array}{c}\% \\
\mathrm{GP}\end{array}$} \\
\hline & Freq & GP & Freq & GP & Freq & GP & Freq & GP & Freq & GP & & & & \\
\hline Alchornea & 7 & 228 & 7 & 35 & 5 & 30 & 1 & 1 & & & 20 & 294 & 9,3 & 17,4 \\
\hline Eucalyptus & 6 & 12 & 4 & 13 & 1 & 34 & 1 & 5 & & & 12 & 64 & 5,6 & 3,8 \\
\hline Euterpe & 4 & 16 & 3 & 5 & 2 & 2 & 1 & 10 & & & 10 & 33 & 4,6 & 2 \\
\hline Mikania & 5 & 9 & 2 & 3 & 1 & 15 & & & & & 8 & 27 & 3,7 & 1,6 \\
\hline Senna & 2 & 27 & 3 & 8 & 3 & 8 & & & & & 8 & 43 & 3,7 & 2,5 \\
\hline Pouteria bullata & 3 & 5 & 1 & 2 & 1 & 1 & 2 & 311 & 1 & 13 & 8 & 332 & 3,7 & 19,6 \\
\hline Myrtaceae & 4 & 12 & 1 & 1 & 1 & 1 & 1 & 5 & & & 7 & 19 & 3,2 & 1,1 \\
\hline Pinus & 5 & 13 & 1 & 1 & & & & & & & 6 & 14 & 2,8 & 0,8 \\
\hline Vernonia & 3 & 59 & 1 & 5 & 1 & 4 & 1 & 2 & & & 6 & 70 & 2,8 & 4,1 \\
\hline Desmodium & 3 & 3 & 1 & 1 & & & 1 & 9 & & & 5 & 13 & 2,3 & 0,8 \\
\hline Poaceae & 3 & 7 & 1 & 1 & 1 & 1 & & & & & 5 & 9 & 2,3 & 0,5 \\
\hline Solanum & 3 & 3 & 2 & 3 & & & & & & & 5 & 6 & 2,3 & 0,4 \\
\hline Zanthoxylum & 2 & 57 & 1 & 2 & 2 & 5 & & & & & 5 & 64 & 2,3 & 3,8 \\
\hline Allophylus & 1 & 1 & 1 & 1 & 2 & 4 & & & & & 4 & 6 & 1,9 & 0,4 \\
\hline Baccharis & 2 & 3 & 1 & 2 & 1 & 2 & & & & & 4 & 7 & 1,9 & 0,4 \\
\hline Brosimum & 3 & 4 & & & 1 & 7 & & & & & 4 & 11 & 1,9 & 0,6 \\
\hline Cecropia pachystachya & 3 & 122 & & & 1 & 1 & & & & & 4 & 123 & 1,9 & 7,3 \\
\hline Cupania & 2 & 17 & 1 & 1 & 1 & 133 & & & & & 4 & 151 & 1,9 & 8,9 \\
\hline Ficus & 3 & 11 & 1 & 1 & & & & & & & 4 & 12 & 1,9 & 0,7 \\
\hline Mimosa bimucronata & 2 & 2 & 2 & 5 & & & & & & & 4 & 7 & 1,9 & 0,4 \\
\hline Schefflera & 2 & 3 & & & 1 & 34 & & & 1 & 3 & 4 & 40 & 1,9 & 2,4 \\
\hline Tibouchina & 2 & 8 & 1 & 2 & 1 & 7 & & & & & 4 & 17 & 1,9 & 1 \\
\hline Cyperus & 1 & 1 & 1 & 1 & 1 & 1 & & & & & 3 & 3 & 1,4 & 0,2 \\
\hline Ilex & 2 & 124 & 1 & 4 & & & & & & & 3 & 128 & 1,4 & 7,6 \\
\hline Mimosa furfuracea & 1 & 3 & 1 & 1 & 1 & 1 & & & & & 3 & 5 & 1,4 & 0,3 \\
\hline Myrcia & 1 & 6 & 1 & 2 & 1 & 31 & & & & & 3 & 39 & 1,4 & 2,3 \\
\hline Piptadenia & 2 & 2 & & & 1 & 1 & & & & & 3 & 3 & 1,4 & 0,2 \\
\hline Protium & & & & & 2 & 2 & 1 & 1 & & & 3 & 3 & 1,4 & 0,2 \\
\hline Tapirira & 2 & 3 & & & 1 & 4 & & & & & 3 & 7 & 1,4 & 0,4 \\
\hline Anacardium & 1 & 2 & 1 & 3 & & & & & & & 2 & 5 & 0,9 & 0,3 \\
\hline
\end{tabular}


Tabela 1 (continuação)

\begin{tabular}{|c|c|c|c|c|c|c|c|c|c|c|c|c|c|c|}
\hline \multirow{2}{*}{$\frac{\text { Espécies }}{\text { Tipos polínicos }}$} & \multicolumn{2}{|c|}{ A. lit } & \multicolumn{2}{|c|}{ S. lil } & \multicolumn{2}{|c|}{ A. fim } & \multicolumn{2}{|c|}{ G. sor } & \multicolumn{2}{|c|}{ P. lin } & \multirow{2}{*}{$\begin{array}{l}\text { Total } \\
\text { Freq }\end{array}$} & \multirow{2}{*}{$\begin{array}{c}\text { Total } \\
\text { GP }\end{array}$} & \multirow{2}{*}{$\begin{array}{c}\% \\
\text { Freq }\end{array}$} & \multirow{2}{*}{$\begin{array}{c}\% \% \\
\text { GP }\end{array}$} \\
\hline & Freq & GP & Freq & GP & Freq & GP & Freq & GP & Freq & GP & & & & \\
\hline Chamaecrista & 1 & 1 & 1 & 1 & & & & & & & 2 & 2 & 0,9 & 0,1 \\
\hline Citrus & & & 1 & 1 & 1 & 34 & & & & & 2 & 35 & 0,9 & 2,1 \\
\hline Clibadium & & & 1 & 2 & 1 & 1 & & & & & 2 & 3 & 0,9 & 0,2 \\
\hline Dalbergia & 1 & 4 & 1 & 1 & & & & & & & 2 & 5 & 0,9 & 0,3 \\
\hline Inga & 1 & 1 & & & & & 1 & 1 & & & 2 & 2 & 0,9 & 0,1 \\
\hline Lithraea & & & 1 & 1 & 1 & 6 & & & & & 2 & 7 & 0,9 & 0,4 \\
\hline Asteraceae & 1 & 4 & & & 1 & 1 & & & & & 2 & 5 & 0,9 & 0,3 \\
\hline Zea mays & 1 & 3 & 1 & 1 & & & & & & & 2 & 4 & 0,9 & 0,2 \\
\hline Araceae & & & & & 2 & 2 & & & & & 2 & 2 & 0,9 & 0,1 \\
\hline Melastomataceae & 1 & 3 & 1 & 2 & & & & & & & 2 & 5 & 0,9 & 0,3 \\
\hline Centrosema & & & 1 & 1 & & & & & & & 1 & 1 & 0,5 & 0,1 \\
\hline Anadenanthera & & & & & 1 & 1 & & & & & 1 & 1 & 0,5 & 0,1 \\
\hline Anthurium & & & 1 & 1 & & & & & & & 1 & 1 & 0,5 & 0,1 \\
\hline Aspidosperma & & & & & 1 & 1 & & & & & 1 & 1 & 0,5 & 0,1 \\
\hline Bauhinia & & & & & & & 1 & 1 & & & 1 & 1 & 0,5 & 0,1 \\
\hline Bidens & & & 1 & 1 & & & & & & & 1 & 1 & 0,5 & 0,1 \\
\hline Bougainvillea & & & 1 & 1 & & & & & & & 1 & 1 & 0,5 & 0,1 \\
\hline Cedrela & 1 & 6 & & & & & & & & & 1 & 6 & 0,5 & 0,4 \\
\hline Chamaesyce & & & 1 & 1 & & & & & & & 1 & 1 & 0,5 & 0,1 \\
\hline Davilla & 1 & 2 & & & & & & & & & 1 & 2 & 0,5 & 0,1 \\
\hline Drymaria & & & & & & & & & 1 & 1 & 1 & 1 & 0,5 & 0,1 \\
\hline Erythroxylum & 1 & 8 & & & & & & & & & 1 & 8 & 0,5 & 0,5 \\
\hline Gomphrena & & & & & 1 & 1 & & & & & 1 & 1 & 0,5 & 0,1 \\
\hline Hyeronima & 1 & 3 & & & & & & & & & 1 & 3 & 0,5 & 0,2 \\
\hline Machaerium & 1 & 5 & & & & & & & & & 1 & 5 & 0,5 & 0,3 \\
\hline Matayba & 1 & 1 & & & & & & & & & 1 & 1 & 0,5 & 0,1 \\
\hline Myrsine & 1 & 1 & & & & & & & & & 1 & 1 & 0,5 & 0,1 \\
\hline Schinus & & & 1 & 3 & & & & & & & 1 & 3 & 0,5 & 0,2 \\
\hline Sonchus & 1 & 1 & & & & & & & & & 1 & 1 & 0,5 & 0,1 \\
\hline Struthanthus & & & & & 1 & 3 & & & & & 1 & 3 & 0,5 & 0,2 \\
\hline Tabebuia & & & 1 & 1 & & & & & & & 1 & 1 & 0,5 & 0,1 \\
\hline Talisia & 1 & 2 & & & & & & & & & 1 & 2 & 0,5 & 0,1 \\
\hline Tetrorchidium & 1 & 1 & & & & & & & & & 1 & 1 & 0,5 & 0,1 \\
\hline Thelypteris & & & & & 1 & 1 & & & & & 1 & 1 & 0,5 & 0,1 \\
\hline Typha & 1 & 1 & & & & & & & & & 1 & 1 & 0,5 & 0,1 \\
\hline Urera & 1 & 4 & & & & & & & & & 1 & 4 & 0,5 & 0,2 \\
\hline Weinmannia & 1 & 2 & & & & & & & & & 1 & 2 & 0,5 & 0,1 \\
\hline Orchidaceae & 1 & 4 & & & & & & & & & 1 & 4 & 0,5 & 0,2 \\
\hline Crotalaria & 1 & 2 & & & & & & & & & 1 & 2 & 0,5 & 0,1 \\
\hline Echium & 1 & 4 & & & & & & & & & 1 & 4 & 0,5 & 0,2 \\
\hline Monocotiledonea & & & 1 & 1 & & & & & & & 1 & 1 & 0,5 & 0,1 \\
\hline Poaceae & 1 & 1 & & & & & & & & & 1 & 1 & 0,5 & 0,1 \\
\hline Total & 103 & 827 & 55 & 122 & 44 & 380 & 11 & 346 & 3 & 17 & 216 & 1692 & 100 & 100 \\
\hline
\end{tabular}


de Fabaceae também foi registrada por Gonçalvez (2009), Silva (2009) e Pinto (2010). As famílias que apresentaram mais tipos polínicos diferentes foram Fabaceae $(n=12)$ e Asteraceae $(n=7)$. As principais famílias vegetais consumidas por morcegos fitófagos no Brasil são Fabaceae, Solanaceae, Moraceae, Piperaceae, Malvaceae, Myrtaceae, Bromeliaceae, Arecaceae, Araceae, Cactaceae, Urticaceae e Sapotaceae (Bredt et al. 2012).

Apesar de terem sido registrados 72 tipos polínicos, 32 deles $(44,4 \%)$ foram encontrados apenas uma vez e com baixa quantidade de grãos de pólen (soma variando de um a três grãos). Os tipos polínicos mais frequentes foram Alchornea $(9,3 \%, \mathrm{n}=20)$ (figura 18), Eucalyptus $(5,6 \%, \mathrm{n}=12)$ (figura 37) e Euterpe $(4,6 \%, \mathrm{n}=10)$ (figura 2) (tabela 1). Em uma amostra de $A$. lituratus foram contabilizados 171 grãos de Alchornea, sugerindo que indivíduos dessa espécie tiveram algum tipo de interação com flores desse gênero. Há registro sobre o consumo de partes florais de Alchornea por morcegos na Colômbia (Bredt et al. 2012), bem como registros de frutos de Alchornea latifolia Sw. na dieta de Artibeus jamaicensis Leach, 1821 e Artibeus intermedius Allen, 1897 (Estrada et al. 2012).

O tipo Eucalyptus foi o segundo mais frequente somando 64 grãos de pólen em 12 amostras, entretanto vale ressaltar que apesar da alta frequência a quantidade de grãos de pólen encontrados por amostras foi baixa, sendo que em $58 \%$ (sete amostras) havia apenas um grão de pólen. Contudo, uma amostra de Artibeus fimbriatus somou 34 grãos, porém no momento há registro sobre o consumo de partes florais de Eucalyptus apenas para Anoura geoffroyi Gray, 1838 e Glossophaga soricina (Bredt et al. 2012).

Euterpe apareceu como o terceiro tipo polínico mais frequente, somando 33 grãos de pólen em dez amostras, no geral apresentou baixa quantidade de grãos por amostras. Na literatura é encontrado registro de consumo de fruto de Euterpe edulis Mart. (palmito-juçara) apenas para A. lituratus no Estado de São Paulo (Bredt et al. 2012). Reis (1995) observou que morcegos preferem consumir frutos de Euterpe edulis quando os mesmos iniciam seu amadurecimento e visto que é possível que haja irregularidades de floração no indivíduo (podendo estar presentes frutos e flores ao mesmo tempo) (Fisch et al. 2000), isso pode favorecer o contato do animal com grãos de pólen desse gênero.

Bauhinia (figura 20) foi o único tipo polínico encontrado nesse estudo que possui síndrome de polinização quiropterofílica, tendo como polinizador G. soricina (Heithaus 1974, Ramírez et al. 1984, Silva et al. 1997). Apesar disso, foi registrado apenas uma vez com um grão de pólen.

Os tipos Brosimum, Cecropia pachystachya, Cyperus, Hyeronima, Pinus, Poaceae, Typha Zea mays possuem síndrome de polinização anemófila (polinização pelo vento), portanto, provavelmente estavam na pelagem dos morcegos de forma acidental. Entretanto, Brosimum (figura 35) e Cecropia pachystachya são plantas que compõem a dieta de A. lituratus e A. fimbriatus (Bredt et al. 2012), assim sendo, o contato com os grãos de pólen pode ter ocorrido no momento em que esses animais estivessem buscando frutos dessas plantas.

Neste trabalho foram identificadas pela primeira vez várias interações entre morcegos e plantas, visto que dos 72 tipos polínicos registrados na pelagem dos morcegos, 60 ainda não apresentam relatos de interação alimentar entre essas espécies de morcegos e essas espécies florais. Essa lacuna de informação está relacionada com a escassez de trabalhos que investigam a relação entre morcegos fitófagos e grãos de pólen, sendo que a maioria dos registros foram descritos fora do Brasil (Bredt et al. 2012). Dentre todos os tipos polínicos encontrados em A. lituratus apenas nove já possuem relatos compondo parte da sua dieta (Anacardium, Euterpe, Senna, Inga, Brosimum, Ficus, Pouteria bullata, Solanum e Cecropia pachystachya) (Bredt et al. 2012). Para A. fimbriatus apenas Cecropia pachystachya consta como item alimentar (Bredt et al. 2012). S. lilium possui interação alimentar já conhecida apenas para Anacardium, Anthurium, Ficus, Pouteria bullata e Solanum (Bredt et al. 2012). P. lineatus não possui registro de interação alimentar com os tipos polínicos aqui registrados e Glossophaga soricina possui interação alimentar com três dos dez tipos polínicos amostrados (Inga, Bauhinia, Eucalyptus) (Bredt et al. 2012).

Algumas interações se destacaram devido a grande quantidade de grãos de pólen encontrada nas amostras, como observado entre os tipos polínicos Alchornea, Ilex, Vernonia e Zanthoxylum encontrados em A. lituratus e Cupania, Schefflera, Eucalyptus, Citrus e Alchornea encontrados em A. fimbriatus. Um indivíduo de G. soricina possuía seu corpo coberto por grãos de pólen de Pouteria bullata (coloração verde), sendo contabilizados mais de 300 grãos nessa amostra. Todos esses casos indicam que o morcego visitou intencionalmente a planta em busca de recursos, 

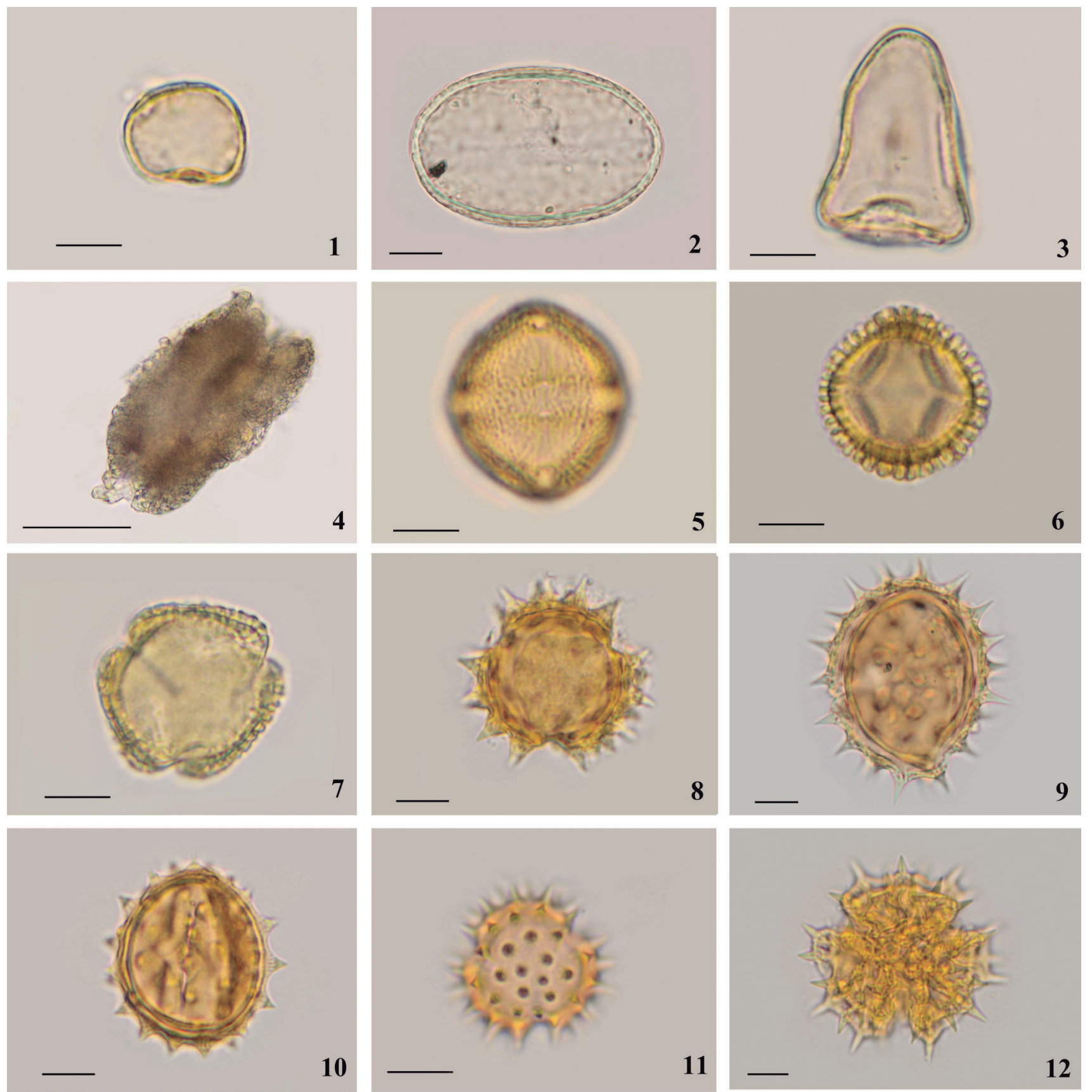

Figuras 1-12. Fotomicrografias de grãos de pólen encontrados em pelagem dos morcegos do Parque Estadual das Fontes do Ipiranga, São Paulo, Brasil. 1-4. Monocotiledôneas. 1. Araceae. 2. Arecaceae: Euterpe. 3. Cyperaceae: Cyperus. 4. Orquidaceae (polínia). 5-12. Eudicotiledôneas. 5. Anacardiaceae: Lythraea. 6. Aquifoliacea: Ilex. 7. Araliaceae: Shefflera. 8-12. Asteraceae: 8. Baccharys. 9. Bidens. 10. Clibadium. 11. Mikania. 12. Vernonia. Escala na figura $4=50 \mu \mathrm{m}$. Demais figuras, escala $=10 \mu \mathrm{m}$.

Figures 1-12. Photomicrographs of pollen grains found on the fur of bats at Parque Estadual Fontes do Ipiranga, São Paulo, São Paulo State, Brazil. 1-4. Monocotyledons. 1. Araceae. 2. Arecaceae: Euterpe. 3. Cyperaceae: Cyperus. 4. Orquidaceae (polínia). 5-12. Eudicotyledons. 5. Anacardiaceae: Lythraea. 6. Aquifoliacea: Ilex. 7. Araliaceae: Shefflera. 8-12. Asteraceae: 8. Baccharys. 9. Bidens. 10. Clibadium. 11. Mikania. 12. Vernonia. Figure 4 scale $=50 \mu \mathrm{m}$. Other figures, scales $=10 \mu \mathrm{m}$. 

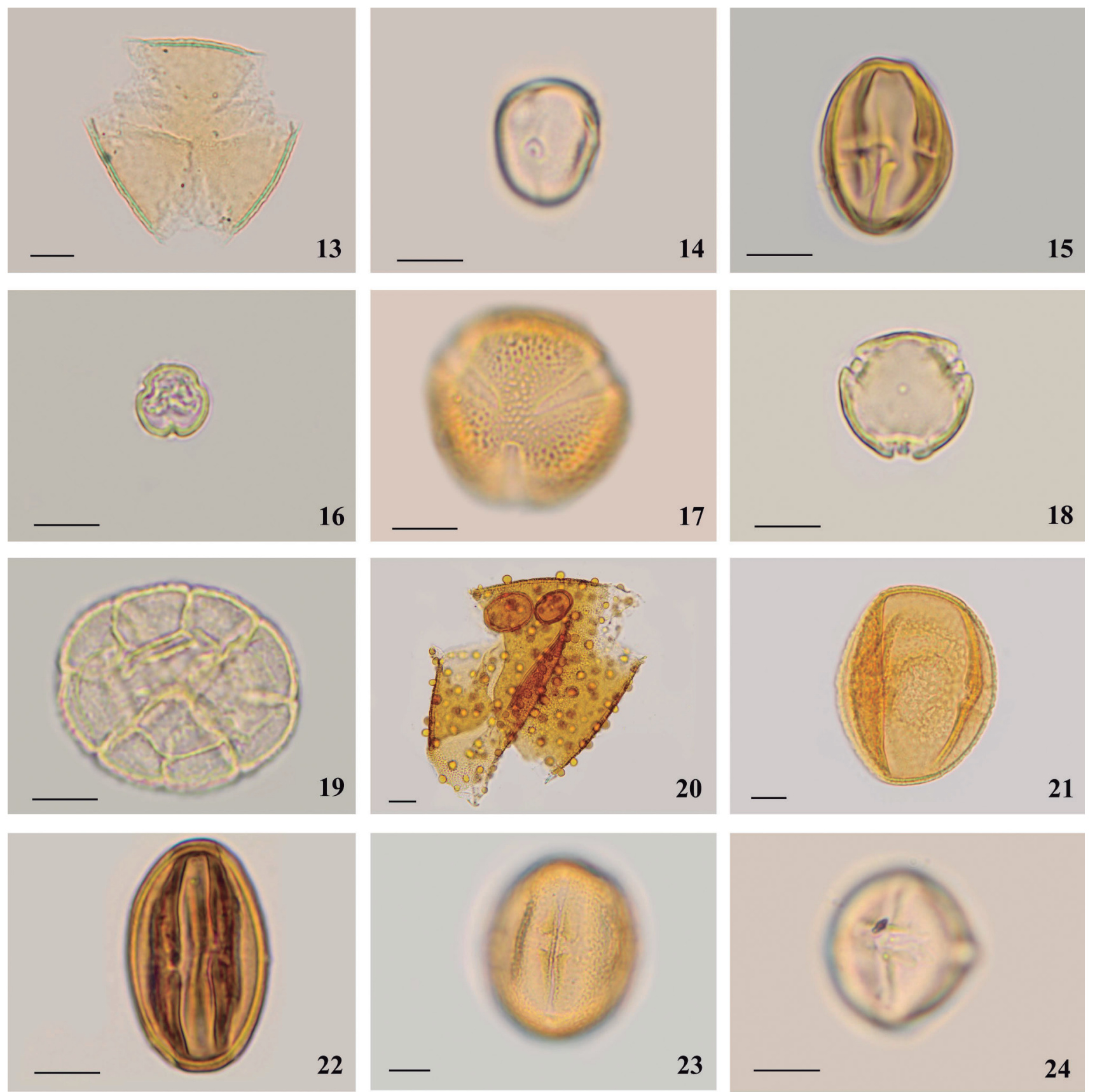

Figuras 13-24. Fotomicrografias de grãos de pólen encontrados em pelagem dos morcegos do Parque Estadual das Fontes do Ipiranga, São Paulo, Brasil. Eudicotiledôneas. 13. Bignoniaceae: Tabebuia. 14. Boraginaceae: Echium. 15. Burseraceae: Protium. 16. Cunoniaceae: Weinmannia. 17. Erythroxylaceae: Erytrhoxylum. 18. Euphorbiaceae: Alchornea. 19-24. Fabaceae: 19. Anadenanthera. 20. Bauhinia. 21. Centrosema. 22. Chamaechrista. 23. Crotalaria. 24. Dalbergia. Escalas nas figuras $=10 \mu \mathrm{m}$.

Figures 13-24. Photomicrographs of pollen grains found on the fur of bats at Parque Estadual Fontes do Ipiranga, São Paulo, São Paulo State, Brazil. Eudicotiledôneas. 13. Bignoniaceae: Tabebuia. 14. Boraginaceae: Echium. 15. Burseraceae: Protium. 16. Cunoniaceae: Weinmannia. 17. Erythroxylaceae: Erytrhoxylum. 18. Euphorbiaceae: Alchornea. 19-24. Fabaceae: 19. Anadenanthera. 20. Bauhinia. 21. Centrosema. 22. Chamaechrista. 23. Crotalaria. 24. Dalbergia. Scales $=10 \mu \mathrm{m}$. 

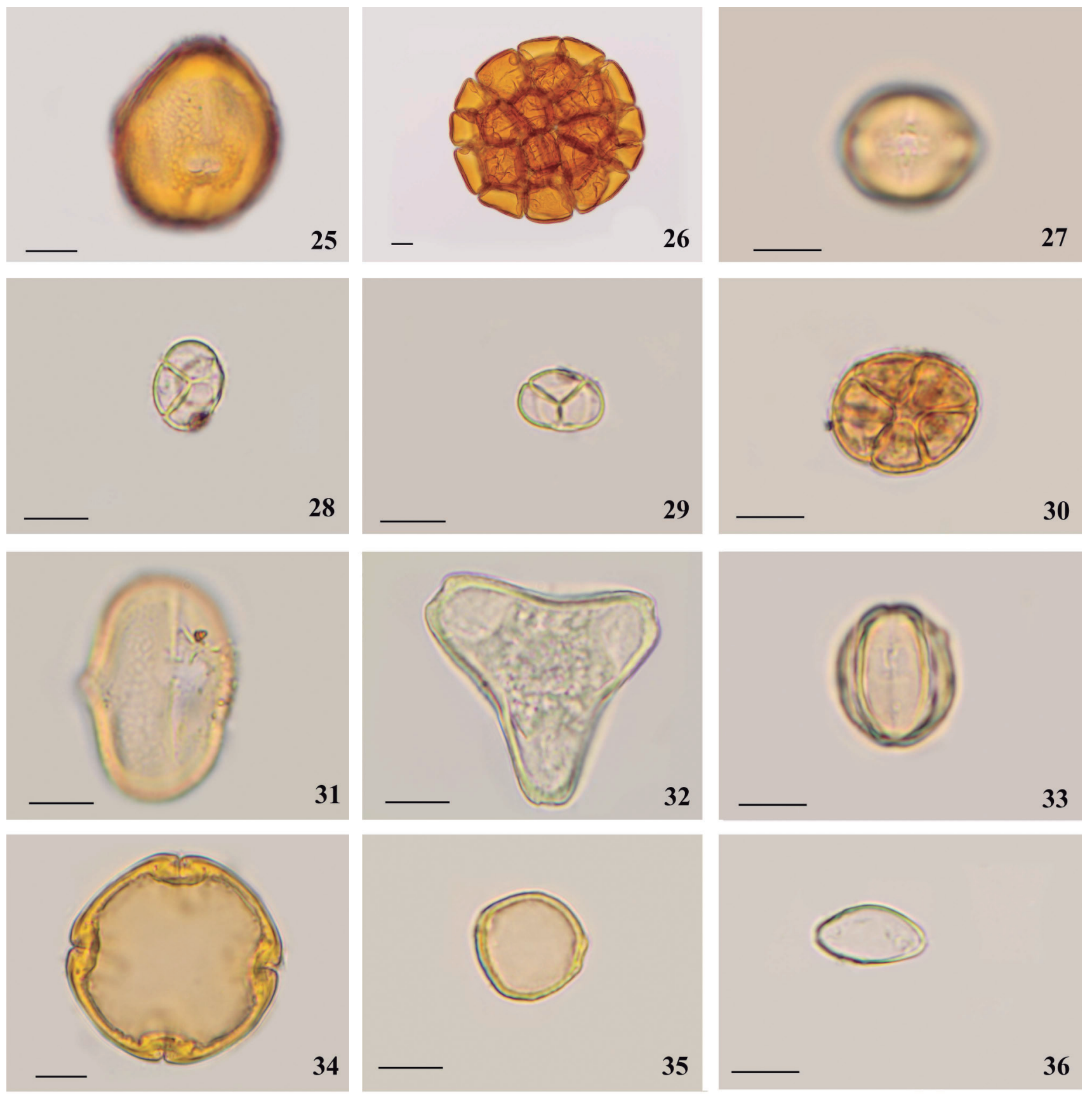

Figuras 25-36. Fotomicrografias de grãos de pólen encontrados em pelagem dos morcegos do Parque Estadual das Fontes do Ipiranga, São Paulo, Brasil. Eudicotiledôneas. 25-31. Fabaceae: 25. Desmodium. 26. Inga (políade). 27. Machaerium. 28. Mimosa bimucronata. 29. Mimosa furfuracea. 30. Piptadenia. 31. Senna. 32. Loranthaceae: Struthanthus. 33. Melastomataceae: Tibouchina. 34. Meliaceae: Cedrela. 35-36. Moraceae: 35. Brosimum. 36. Ficus. Escala na figura $26=20 \mu \mathrm{m}$. Demais figuras, escala $=10 \mu \mathrm{m}$.

Figures 25-36. Photomicrographs of pollen grains found on the fur of bats at Parque Estadual Fontes do Ipiranga, São Paulo, São Paulo State, Brazil. Eudicotyledons. 25-31. Fabaceae: 25. Desmodium. 26. Inga (políade). 27. Machaerium. 28. Mimosa bimucronata. 29. Mimosa furfuracea. 30. Piptadenia. 31. Senna. 32. Loranthaceae: Struthanthus. 33. Melastomataceae: Tibouchina. 34. Meliaceae: Cedrela. 35-36. Moraceae: 35. Brosimum. 36. Ficus. Figure 26 scale $=50 \mu \mathrm{m}$. Other figures, scales $=10 \mu \mathrm{m}$ 

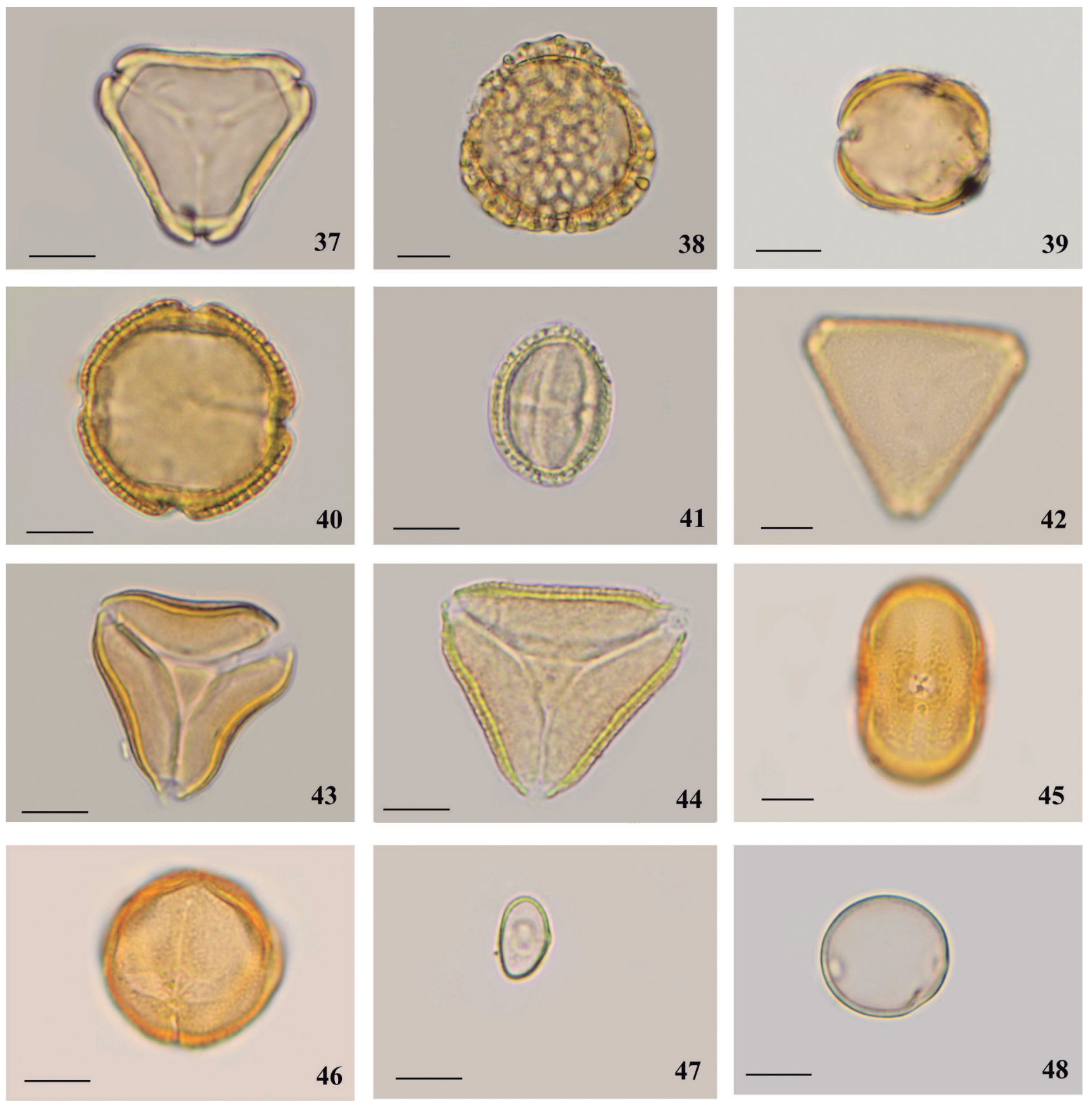

Figuras 37-48. Fotomicrografias de grãos de pólen encontrados em pelagem dos morcegos do Parque Estadual das Fontes do Ipiranga, São Paulo, Brasil. Eudicotiledôneas. 37. Myrtaceae: Eucalyptus. 38. Nictaginaceae: Bougainvillea. 39. Primulaceae: Myrsine. 40-41. Rutaceae: 40. Citrus. 41. Zanthoxylum. 42-44: Sapindaceae: 42. Allophylus. 43. Cupania. 44. Matayba. 45. Sapotaceae: Pouteria bullata. 46. Solanaceae: Solanum. 47-48. Urticaceae: 47. Cecropia pachystachya. 48. Urera. Escalas nas figuras $=10 \mu \mathrm{m}$.

Figures 37-48. Photomicrographs of pollen grains found on the fur of bats at Parque Estadual Fontes do Ipiranga, São Paulo, São Paulo State, Brazil. Eudicotyledons. 37. Myrtaceae: Eucalyptus. 38. Nictaginaceae: Bougainvillea. 39. Primulaceae: Myrsine. 40-41. Rutaceae: 40. Citrus. 41. Zanthoxylum. 42-44: Sapindaceae: 42. Allophylus. 43. Cupania. 44. Matayba. 45. Sapotaceae: Pouteria bullata. 46. Solanaceae: Solanum. 47-48. Urticaceae: 47. Cecropia pachystachya. 48. Urera. Scales $=10 \mu \mathrm{m}$. 
caracterizando a interação entre essas espécies e identificado-as pela primeira vez.

Influência da sazonalidade sobre a diversidade polínica nos morcegos - Na estação chuvosa foram registrados $90,3 \%$ do total de grãos de pólen amostrados na pelagem dos morcegos $(\mathrm{n}=1.528)$, também houve maior número de tipos polínicos diferentes registrados $(\mathrm{n}=6083,3 \%)$ e a frequência de ocorrência dos tipos polínicos representou $68 \%(\mathrm{n}=147)$. Já a estação seca somou apenas 164 grãos de pólen $(9,7 \%)$, com 34 $(47,2 \%)$ tipos polínicos amostrados e $31,9 \%(n=69)$ da frequência de ocorrência dos tipos polínicos (tabela 2 ). De acordo com o teste o estatístico aplicado houve diferença altamente significativa na quantidade de pólen amostrada entre as estações $(\mathrm{F}=101,0198914$ e $\mathrm{p}=0,000572709$, ao nível de significância $0,05 \%$ ).
A análise da sazonalidade indicou grande influência da estação chuvosa na presença de pólen nos corpos dos morcegos, corroborando com os diversos estudos fenológicos realizados no sudeste brasileiro, os quais apontam uma correlação entre a estação com maior pluviosidade com o maior número de espécies em floração (Morellato et al. 1989, Morellato \& LeitãoFilho 1992, Ferraz et al. 1998, Talora \& Morellato 2000). Além disso, já foi constatado o maior consumo de pólen e néctar por morcegos nessa estação (Pedro \& Taddei 1997).

Dentre os tipos polínicos encontrados, 22 ocorreram em ambas às estações, 38 somente no período chuvoso e 12 apenas no período seco. Alchornea apresentou 89\% $(n=263)$ de seus grãos de pólen na estação chuvosa. Embora Eucalyptus

Tabela 2. Tipos polínicos encontrados na pelagem de morcegos Phyllostomidae durante as estações chuvosa e seca, com suas respectivas frequências de ocorrências (Freq) e quantidade de grãos de pólen de cada tipo polínico (GP), no Parque Estadual Fontes do Ipiranga, São Paulo, SP, Brasil, entre outubro de 2015 e setembro 2016.

Table 2. Pollen types found on the fur of Phyllostomidae bats during dry and rainy seasons, with the respective frequency of occurrence (Freq) and the amount of pollen grain of each pollen type (GP) at theParque Estadual Fontes do Ipiranga, São Paulo, São Paulo State, Brazil, between October 2015 and September 2016.

\begin{tabular}{lcccccccc}
\hline Estação & \multicolumn{3}{c}{ Chuvosa } & & & Seca & \multicolumn{3}{c}{ Total } \\
\hline Tipo Polínico & Freq & $\%$ & GP & Freq & $\%$ & GP & Freq & $\%$ \\
\hline Alchornea & 12 & 8,2 & 263 & 8 & 11,6 & 31 & 20 & 9,3 \\
Eucalyptus & 5 & 3,4 & 45 & 7 & 10,1 & 19 & 12 & 5,6 \\
Euterpe & 7 & 4,8 & 24 & 3 & 4,3 & 9 & 10 & 4,6 \\
Mikania & 6 & 4,1 & 25 & 2 & 2,9 & 2 & 8 & 3,7 \\
Senna & 6 & 4,1 & 38 & 2 & 2,9 & 5 & 8 & 3,7 \\
Pouteria bullata & 5 & 2,7 & 314 & 3 & 2,9 & 15 & 8 & 3,7 \\
Myrtaceae & 4 & 2,7 & 8 & 3 & 4,3 & 11 & 7 & 3,2 \\
Pinus & 2 & 1,4 & 3 & 4 & 5,8 & 11 & 6 & 2,8 \\
Solanum & 2 & 1,4 & 2 & 3 & 4,3 & 4 & 5 & 2,3 \\
Desmodium & 1 & 0,7 & 1 & 4 & 5,8 & 12 & 5 & 2,3 \\
Allophylus & 3 & 2 & 5 & 1 & 1,4 & 1 & 4 & 1,9 \\
Cecropia pachystachya & 3 & 2 & 122 & 1 & 1,4 & 1 & 4 & 1,9 \\
Mimosa bimucronata & 3 & 2 & 6 & 1 & 1,4 & 1 & 4 & 1,9 \\
Schefflera & 3 & 2 & 39 & 1 & 1,4 & 1 & 4 & 1,9 \\
Baccharis & 2 & 1,4 & 4 & 2 & 2,9 & 3 & 4 & 1,9 \\
Ficus & 2 & 1,4 & 6 & 2 & 2,9 & 6 & 4 & 1,9 \\
Chamaecrista & 2 & 1,4 & 2 & 1 & 1,4 & 1 & 3 & 1,4 \\
Cyperus & 2 & 1,4 & 2 & 1 & 1,4 & 1 & 3 & 1,4 \\
Piptadenia & 1 & 0,7 & 1 & 2 & 2,9 & 2 & 3 & 1,4 \\
Tapirira & 2 & 1,4 & 6 & 1 & 1,4 & 1 & 3 & 1,4 \\
Inga & 1 & 0,7 & 1 & 1 & 1,4 & 1 & 2 & 0,9
\end{tabular}


Tabela 2 (continuação)

\begin{tabular}{|c|c|c|c|c|c|c|c|c|}
\hline \multirow{2}{*}{$\frac{\text { Estação }}{\text { Tipo Polínico }}$} & \multicolumn{3}{|c|}{ Chuvosa } & \multicolumn{3}{|c|}{ Seca } & \multicolumn{2}{|c|}{ Total } \\
\hline & Freq & $\%$ & GP & Freq & $\%$ & GP & Freq & $\%$ \\
\hline Zea mays & 1 & 0,7 & 3 & 1 & 1,4 & 1 & 2 & 0,9 \\
\hline Vernonia & 6 & 4,1 & 70 & & & & 6 & 2,8 \\
\hline Poaceae & 5 & 3,4 & 9 & & & & 5 & 2,3 \\
\hline Zanthoxylum & 5 & 3,4 & 64 & & & & 5 & 2,3 \\
\hline Brosimum & 4 & 2,7 & 11 & & & & 4 & 1,9 \\
\hline Cupania & 4 & 2,7 & 151 & & & & 4 & 1,9 \\
\hline Tibouchina & 4 & 2,7 & 17 & & & & 4 & 1,9 \\
\hline Ilex & 3 & 2 & 128 & & & & 3 & 1,4 \\
\hline Mimosa furfuracea & 3 & 2 & 5 & & & & 3 & 1,4 \\
\hline Myrcia & 3 & 2 & 39 & & & & 3 & 1,4 \\
\hline Anacardium & 2 & 1,4 & 5 & & & & 2 & 0,9 \\
\hline Citrus & 2 & 1,4 & 35 & & & & 2 & 0,9 \\
\hline Clibadium & 2 & 1,4 & 3 & & & & 2 & 0,9 \\
\hline Lithraea & 2 & 1,4 & 7 & & & & 2 & 0,9 \\
\hline Asteraceae & 2 & 1,4 & 3 & & & & 2 & 0,9 \\
\hline Araceae & 2 & 1,4 & 2 & & & & 2 & 0,9 \\
\hline Anadenanthera & 1 & 0,7 & 1 & & & & 1 & 0,5 \\
\hline Anthurium & 1 & 0,7 & 1 & & & & 1 & 0,5 \\
\hline Bauhinia & 1 & 0,7 & 1 & & & & 1 & 0,5 \\
\hline Bougainvillea & 1 & 0,7 & 1 & & & & 1 & 0,5 \\
\hline Cedrela & 1 & 0,7 & 6 & & & & 1 & 0,5 \\
\hline Davilla & 1 & 0,7 & 2 & & & & 1 & 0,5 \\
\hline Drymaria & 1 & 0,7 & 1 & & & & 1 & 0,5 \\
\hline Erythroxylum & 1 & 0,7 & 8 & & & & 1 & 0,5 \\
\hline Gomphrena & 1 & 0,7 & 1 & & & & 1 & 0,5 \\
\hline Hyeronima & 1 & 0,7 & 3 & & & & 1 & 0,5 \\
\hline Machaerium & 1 & 0,7 & 5 & & & & 1 & 0,5 \\
\hline Matayba & 1 & 0,7 & 1 & & & & 1 & 0,5 \\
\hline Schinus & 1 & 0,7 & 3 & & & & 1 & 0,5 \\
\hline Struthanthus & 1 & 0,7 & 3 & & & & 1 & 0,5 \\
\hline Tabebuia & 1 & 0,7 & 1 & & & & 1 & 0,5 \\
\hline Talisia & 1 & 0,7 & 2 & & & & 1 & 0,5 \\
\hline Tetrorchidium & 1 & 0,7 & 1 & & & & 1 & 0,5 \\
\hline Thelypteris & 1 & 0,7 & 1 & & & & 1 & 0,5 \\
\hline Typha & 1 & 0,7 & 1 & & & & 1 & 0,5 \\
\hline Weinmannia & 1 & 0,7 & 2 & & & & 1 & 0,5 \\
\hline Orchidaceae & 1 & 0,7 & 4 & & & & 1 & 0,5 \\
\hline Crotalaria & 1 & 0,7 & 2 & & & & 1 & 0,5 \\
\hline Echium & 1 & 0,7 & 4 & & & & 1 & 0,5 \\
\hline Protium & & & & 3 & 4,3 & 3 & 3 & 1,4 \\
\hline Dalbergia & & & & 2 & 2,9 & 5 & 2 & 0,9 \\
\hline Melastomataceae & & & & 2 & 2,9 & 5 & 2 & 0,9 \\
\hline
\end{tabular}


Tabela 2 (continuação)

\begin{tabular}{|c|c|c|c|c|c|c|c|c|}
\hline \multirow{2}{*}{$\frac{\text { Estação }}{\text { Tipo Polínico }}$} & \multicolumn{3}{|c|}{ Chuvosa } & \multicolumn{3}{|c|}{ Seca } & \multicolumn{2}{|c|}{ Total } \\
\hline & Freq & $\%$ & GP & Freq & $\%$ & GP & Freq & $\%$ \\
\hline Centrosema & & & & 1 & 1,4 & & 1 & 0,5 \\
\hline Aspidosperma & & & & 1 & 1,4 & 1 & 1 & 0,5 \\
\hline Bidens & & & & 1 & 1,4 & 1 & 1 & 0,5 \\
\hline Chamaesyce & & & & 1 & 1,4 & 1 & 1 & 0,5 \\
\hline Myrsine & & & & 1 & 1,4 & 1 & 1 & 0,5 \\
\hline Sonchus & & & & 1 & 1,4 & 1 & 1 & 0,5 \\
\hline Urera & & & & 1 & 1,4 & 4 & 1 & 0,5 \\
\hline Poaceae & & & & 1 & 1,4 & 1 & 1 & 0,5 \\
\hline Total (Freq de ocorr) & 147 & & & 69 & & & 216 & \\
\hline Total (Tipos polínicos) & 60 & & 1528 & 34 & & 164 & 72 & \\
\hline
\end{tabular}

tenha apresentado maior quantidade de grãos de pólen na estação chuvosa $(70,3 \%, \mathrm{n}=64)$ esse resultado decorreu de uma amostra de $A$. fimbriatus contendo 34 grãos, pois no geral foram encontradas baixas quantidades de grãos em ambas as estações. Além disso, o pico de floração para esse gênero ocorre durante a estação seca (Vidal et al. 2008). Os grãos de pólen de Euterpe também foram obtidos, majoritariamente, na estação chuvosa $(73 \% \mathrm{n}=24)$, corroborando com IPE (2017) que indica pico de floração no meio da estação chuvosa. Já Vernonia $(4,1 \%)$ e Zanthoxylum $(3,4 \%)$ foram os mais frequentes apenas na estação chuvosa, assim como, Protium (4,3\%), Dalbergia (2,9\%) e Indeterminado (Melastomataceae) (2,9\%) foram os mais frequentes apenas na estação seca, embora com baixa frequência nas amostras.

Constatou-se que os morcegos do PEFI apresentaram grande diversidade polínica em sua pelagem, inclusive com a maioria dos tipos polínicos registrados pela primeira vez nos corpos dessas espécies de quirópteros. Dessa forma, os resultados do presente estudo indicam uma demanda em pesquisas que possam investigar melhor as relações entre essas espécies de morcegos e as plantas das quais eles carregaram os tipos polínicos. Buscando preencher as lacunas do conhecimento dentro dessa área de modo a auxiliar no desenvolvimento de estratégias de conservação mais eficientes, tanto para quiropterofauna como para a flora relacionada a esses animais. Os resultados também indicaram que a metodologia utilizada para a coleta do material polínico em pelagem de morcegos é eficiente e se apresenta como uma alternativa viável para esse tipo de pesquisa.

\section{Agradecimentos}

A Fundação Parque Zoológico de São Paulo, pelas bolsas concedias e por todos os materiais de campo concedidos. A Patrícia Locosque, Carolina Chagas, Paula Andrada e Irys Lima da Divisão de Pesquisas Aplicadas, por fornecerem água destilada, álcool e simpatia. A Kayna Agostini e Natália Seneda Martarello, pela fundamental contribuição com relação ao sistema de polinização das plantas desse trabalho. À Priscila Orlandini, pelos gentis esclarecimentos de dúvidas referentes à Botânica. Ao Luiz Eduardo Moschini, pela confecção do mapa da área desse estudo. À Marina Schweizer, Letícia Mendes, Caio Góis, Gabriela Gerolomo, Luisa Bontorin Beltrame, Julia Vaz, Gedimar Barbosa, Alessandra Mello Souza, Vinícius Cardoso Cláudio, Rachel Venturinni, Rodrigo Alarcon, Karin Saito, Marjory Spina, AmandaAlves, Edson Matsuda e Patrícia Lobo, pelo auxílio nos trabalhos em campo.

\section{Literatura citada}

Barth, O.M. 1989.O pólen no mel brasileiro. Instituto Oswaldo Cruz, Rio de Janeiro.

Bredt,A., Uied, W. \& Pedro, W.A. 2012. Plantas e morcegos: na recuperação de áreas degradadas e na paisagem urbana. Brasília. Rede de Sementes do Cerrado, Brasília.

Buzato, S. \& Franco,A.L.M. 1992. Tetrastylis ovalis: a second case of bat-pollinated passionflower (Passifloraceae). Plant Systematics and Evolution 181: 261-267.

Coelho, D.C. \& Marinho-Filho J. 2002. Diet and activity of Lonchophylla dekeyseri (Chiroptera, Phyllostomidae) in the Federal District, Brazil. Mammalia 66: 319-330.

Carvalho, W.D., Freitas, L.N., Freitas, G.P., Luz, J.L., Costa, L.M., \& Esbérard, C.E.L. 2011. Efeito da chuva na captura de morcegos em uma ilha da costa sul do Rio de Janeiro, Brasil. Chiroptera Neotropical 17: 808-816. 
De Klerk, P. \& Joosten, H. 2007. The difference between pollen types and pollen taxa: a plea for clarity and scientific freedom. Quaternary Science Journal 56: 24-33.

Erdtman, G. 1960. The acetolysis method: a revised description. Svensk Botanisk Tidskrift 54: 561-564.

Estêvão, J.R. 2009. Interação multualista entre morcegos nectarívoros (Chiroptera) e a pata-de-vaca Bauhinia Holophylla Steud.(Fabaceae) em uma área de cerrado: atração e recompensa. Dissertação de Mestrado, Universidade Federal de São Carlos, São Carlos.

Estrada, C.G., Damon A., Hernández, C.S., Pinto, L.S., \& Núnez, G.I. 2012. Diets of frugivorous bats in montane rain forest and coffee plantations in Southeastern Chiapas, Mexico. Biotropica 44: 394-401.

Ferraz, D.K., Artes, R., Mantovani, W. \& Magalhìes, L.M. 1998. Fenologia de árvores em fragmento de mata em São Paulo, SP. Revista Brasileira de Biologia 59: 305-317.

Fischer, E. A. 1992. Foraging of nectarivorous bats on Bauhinia ungulata. Biotropica 24: 579-582.

Fisch, S.T.V., Nogueira Jr., L.R., Mantovani, W. 2000. Fenologia reprodutiva de Euterpe edulis Mart. na Mata Atlântica (Reserva Ecológica do Trabiju, Pindamonhangaba - SP). Revista de biociências 6: 31-37.

Fleming, T.H., Geiselman, C. \& Kress, W.J. 2009. The evolution of bat pollination: a phylogenetic perspective. Annals of Botany 104: 1017-1043.

Gonçalvez, F. 2009. Morcegos vetores de pólen e dispersores de sementes no Pantanal. Dissertação de Mestrado, Universidade Federal de Mato Grosso do Sul, Campo Grande.

Heithaus, E.R. 1974. The role of plant-pollinator interactions in determining community structure. Annals of the Missouri Botanical Garden 61: 675-691.

Heithaus, E.R., Fleming, T.H. \& Opler, P.A. 1975. Foraging patterns and resource utilization in seven species of bats in a seasonal tropical forest. Ecology 56: 841-854.

IAG/USP (Instituto de Astronomia, Geofísica e Ciências Atmosféricas da Universidade de São Paulo). 2016. Boletim Climatológico Anual da Estação Meteorológica do IAG/USP/Seção Técnica de Serviços Meteorológicos. v 19. São Paulo.

Joosten, H. \& De Klerk, P. 2002. What's in a name? Some thoughts on pollen classification, identification, and nomenclature in Quaternary palynology. Review of Palaeobotany and Palynology 122: 29-45.

MacSwiney M.C.G., Bolívar-Cimé, B., Alfaro-Bates R., Ortíz-Díaz, J.J., Clarke F.M. \& Racey P.A. 2017. Pollen movement by the bat Artibeus jamaicensis (Chiroptera) in an agricultural landscape in the Yucatan Peninsula, Mexico. Mammal research 2: 189-193.
Melhem, T.S., Makino, H., Silvestre, M.S.F., Cruz, M.A.V. \& Jung-Mendaçolli, S.L. 1984. Planejamento para a elaboração da "Flora Polínica da Reserva do Parque Estadual das Fontes do Ipiranga (São Paulo, Brasil)". Hoehnea 11: 1-7.

Melhem, T.S., Cruz-Barros, M.A.V., Corrêa, A.M.S., Makino-Watanabe, H., Silvestre-Capelato, M.S.F. \& Esteves, V.L.G. 2003. Variabilidade polínica em plantas de Campos do Jordão (São Paulo, Brasil). Boletim do Instituto de Botânica 16: 1-104.

Melhem, T.S., Giulietti, A.M., Forero, E., Barroso, G.M., Silvestre, M.S.F., Jung, S.L., Makino, H., Melo, M.M.R.F., Chiea, S.C., Wanderley, M.G.L., Kirizawa, M. \& Muniz, C. 1981. Planejamento para a elaboração da "Flora Fanerogâmica da Reserva do Parque Estadual das Fontes do Ipiranga (São Paulo, Brasil)". Hoehnea 9: 63-74.

Mello, M.A.R., Kalko, E.K.V. \& SILVA, W.R. 2008. Diet and abundance of the bat Sturnira lilium (Chiroptera) in a Brazilian Montane Atlantic Forest. Journal of Mammalogy 89: 485-492.

Morellato, L.P.C., Rodrigues, R.R., Leitão-Filho, H.F. \& Joly, C.A. 1989. Estudo fenológico comparativo de espécies arbóreas de floresta de altitude e floresta mesófila semidecídua na Serra do Japi, Jundiaí, SP. Revista Brasileira de Botânica 12: 85-98.

Morellato, L.P.C. \& Leitão-Filho, H.F. 1992. Padrões de frutificação e dispersão na Serra do Japi. In: L.P.C. Morellato (org.). História natural da Serra do Japi: ecologia e preservação de uma área florestal no Sudeste do Brasil. Editora da Unicamp/FAPESP, Campinas, pp.112-140.

Muchhala, N. \& Jarrín-V, P. 2002. Flower visitation by bats in cloud forests of Western Ecuador. Biotropica 34: 387-395.

Nakajima, J.N., Esteves, R.L., Gonçalves-Esteves, V., Magenta, M.A.G., Bianchini, S., Pruski, J. F. \& Hind, D.J.N. 2001. Flora Fanerogâmica da Reserva do Parque Estadual das Fontes do Ipiranga (São Paulo, Brasil).159-Asteraceae. Hoehnea 28: 111-181.

Novaes, R.L.M., Souza, R.F., Felix, S., Siqueira, A.C., Laurindo, R.S., Menezes, L.F. \& Shapiro, J.T. 2016. Seasonality and habitat influence on bat assemblage structure in an urban Atlantic Forest remnant from Southeastern Brazil. Mammalia 81: 265-274.

Pedro, W.A. 1998. Diverdidade de morcegos em habitats florestais fragmentados do Brasil (Chiroptera, Mammalia). Tese de Doutorado, Universidade Federal de São Carlos, São Carlos.

Pedro, W.A. \& Taddei, V.A. 1997. Taxonomic assemblages of bats from Panga Reserve, Southeastern Brazil: abundance patterns and trophic relations in the Phyllostomidae (Chiroptera). Boletim do Museu de Biologia Mello Leitão 6: 3-21. 
Pinto, C.G.C. 2010. Assembléia de morcegos (Mammalia: Chiroptera) e suas interações com plantas quiropterófilas no Parque Nacional Cavernas do Peruaçu, norte de Minas Gerais. Dissertação de Mestrado, Universidade Federal de Lavras, Lavras.

Pinto, C.G.C., Luz, C.F.P. \& Gregorin, R. 2010. Análise de pólen em pelagem de morcegos nectarívoros do Parque Nacional Cavernas do Peruaçu, Minas Gerais, Brasil. Chiroptera Neotropical 16: 83-85.

Ramirez, N., Sobrevila, C., Enrech, N.X. \& Zapata, T.R. 1984. Floral biology and breeding systems of Bauhinia benthamiana TAUB. (Leguminosae) a bat-pollinated tree in Venezuelan "Llanos". American Journal of Botany 71: 273-280.

Reis,A. 1995. Dispersão de sementes de Euterpe edulis Martius - (Palmae) em uma Floresta Ombrófila Densa Montana da Encosta Atântica em Blumenau, SC. Tese de Doutorado, Universidade Estadual de Campinas, Campinas.

Rossi, H.R.S. 2017. Comunidade de morcegos e análise de pólen em pelagem de Phyllostomidae (Chiroptera, Phyllostomidae) no Parque Estadual Fontes do Ipiranga - PEFI, São Paulo, Brasil. Dissertação de Mestrado, Universidade Federal de São Carlos, São Carlos.

Roubik, D.W. \& Moreno P.J.E. 1991. Pollen and spores of Barro Colorado Island. Monographs in Systematic Botany 36: 1-268.

Sanmartin-Gajardo, I. \& Sazima, M. 2005. Chiropterophily in Sinningieae (Gesneriaceae): Sinningia brasiliensis and Paliavana prasinata are batpollinated, but $P$. sericiflora is not. Not yet?. Annals of Botany 95: 1097-1103.
SMA (Secretaria do Meio Ambiente do Estado de São Paulo). 2008. Parque Estadual Fontes do Ipiranga. Plano de Manejo - Resumo Executivo. São Paulo.

Sazima, I. \& Sazima, M. 1977. Solitary and group foraging: two owervisiting patterns of the lesser spear-nosed bat, Phyllostomus discolor. Biotropica 9: 213-215.

Sazima, M. \& Sazima, I. 1978. Bat pollination of the passion flower. Passiflora mucronata in southeastern Brazil. Biotropica 10: 100-109.

Sazima, M., Buzato, S. \& Sazima, I. 1999. Bat-pollinated flower assemblages and bat visitors at two Atlantic Forest sites in Brazil. Annals of Botany 83: 705-712.

Silva, H.C.S.S. 2009. Comunidade de morcegos, interações com flores e estratificação vertical em Mata Atlântica do Sul do Brasil. Dissertação de Mestrado, Universidade Estadual de Campinas, Campinas.

Silva, S.S.P., Peracchi, A.L. \& Aragão, A.O. 1997. Visita de Glossophaga soricina (PALLAS, 1766) às flores de Bauhinia cupulata Benth (LEGUMINOSAE, CAESALPINOIDEAE). Revista Brasileira de Biologia 57: 89-92.

Straube, F.C. \& Bianconi, G.V. 2002. Sobre a grandeza e a unidade utilizada para estimar esforço de captura com utilização de redes-de-neblina. Chiroptera Neotropical 8: $150-152$.

Talora, D.C. \& Morellato, P.C. 2000. Fenologia de espécies arbóreas em floresta de planície litorânea do sudeste do Brasil. Revista Brasileira de Botânica 23: 13-26.

Vidal, M.G., Santana, N.S. \& Vidal, D. 2008. Flora apícola e manejo de apiários na região do recôncavo sul da Bahia. RevistaAcadêmica Ciências Agrárias e Ambiente 6: 503-509.

Vieira, M.F. \& De Carvalho-Okano, R.M. 1996. Pollination biology of Mabea fistulifera (Euphorbiaceae) in Southeastern Brazil. Biotropica 28: 61-68. 